\title{
Earlier Arctic springs cause phenological mismatch in long-distance migrants
}

\author{
Kevin Kuhlmann Clausen • Preben Clausen
}

Received: 9 November 2012/Accepted: 29 April 2013/Published online: 10 May 2013

(C) Springer-Verlag Berlin Heidelberg 2013

\begin{abstract}
An uneven change in climate across the Northern Hemisphere might severely affect the phenology of migrating animals, and especially long-distance migrating birds relying on local climatic cues to regulate the timing of migration. We examine the forward displacement of spring in both staging areas and breeding grounds of one such population, the East Atlantic lightbellied brent goose Branta bernicla hrota, and evaluate to what extent their migration has made a proportional response. On the breeding grounds in Svalbard the onset of spring advanced 2 weeks during the 24-year period, whereas no significant trend was found in the temperate staging areas. The timing of migration was constant throughout the study period, mirroring the static climatic conditions in the spring staging areas. These findings indicate a global warming-induced phenological mismatch in light-bellied brent geese, as these might arrive on their breeding grounds well beyond optimal breeding conditions. Our data indicated that productivity was negatively influenced by phenological delay and positively influenced by prolonged snow cover. We argue that both these effects might be representative of a negative influence of the growing phenological mismatch, because years with later thaw might partly offset the effects of increasingly earlier Svalbard springs. During the study period reproduction fell below annual mortality, and the population declined in recent years. The wider implications of these findings may extend to many migrating species, and highlight the urgent
\end{abstract}

Communicated by Hannu Pöysä.

K. K. Clausen $(\varangle) \cdot$ P. Clausen

Department of Bioscience, Aarhus University, Grenåvej 14, 8410 Rønde, Denmark

e-mail: kc@dmu.dk need to clarify how global change may influence cues and the associated timing of important life history activities.

Keywords Climate change $\cdot$ Phenology $\cdot$ Advancing spring $\cdot$ Svalbard $\cdot$ Branta bernicla hrota

\section{Introduction}

The on-going impacts of climate change on natural ecosystems are a growing and worldwide concern for the ecology, conservation and management of many species (Watkinson et al. 2004; Dickey et al. 2008; Post et al. 2009). To birds and animals living in high-Arctic areas these issues are of even greater importance, as the effects of global warming and resultant climatic change have been shown to amplify towards the North Pole (Høye et al. 2007; IPCC 2007; Ward et al. 2009). Although the natural evolution of individual species has a long history of coping with climatic changes and environmental stress, a continuing accumulation of scientific evidence suggests that present global warming proceeds at a rate well beyond the adaptive capabilities of natural evolutionary processes (Visser 2008).

One clear and potentially far-reaching effect of these changes has been an advancing onset of spring at higher latitudes (Lehikoinen et al. 2004; Nordli 2005). This development has affected the growing season, seasonal weather patterns and biotic interactions in Arctic ecosystems (Bêty et al. 2001; Dickey et al. 2008; Karlsen et al. 2010), and direct effects on permanent wildlife of the Arctic region is well documented (Callaghan et al. 2004). Furthermore, the uneven impact of climate change across the Northern Hemisphere can cause significant regional differences in the forward displacement of spring (Stone et al. 
2002; IPCC 2007), and may therefore influence long-distance migrants in different ways depending on where they are in their annual cycle. This might interrupt phenological movements evolved to optimise seasonal patterns of local climate and food abundance. Long-distance migrating birds are especially sensitive to regional differences in climatic change. Because the spring migration of these species may depend on proximate factors in the winter staging areas (Tombre et al. 2008), geographically restricted climatic changes may result in migration patterns out of sync with actual seasonal advancement at the other end of the flyway. Ultimately, these differences can cause a mismatch between seasonal progress and actual arrival of migrating birds, potentially interrupting adaptations to the timing of optimal breeding conditions (Pearce-Higgins et al. 2005).

Western Palearctic migrating bird species potentially affected by the latitude-dependent climate change include a large group of Anatidae species breeding in the Arctic (Northeast Canada, Greenland, Svalbard and Northern Russia) while wintering in temperate and sub-tropical regions (Europe, Middle East and Northern Africa) (Scott and Rose 1996). In Northwest Europe several species of geese exhibit this pattern of migration, hence, potentially are exposed to phenological mismatches in their annual cycle. Broad distributions and flyways, mixed populations and the use of remote stopover sites en route are typical characteristics of many of these populations (Madsen et al. 1999). Nevertheless, a well-defined population with distinct migration routes, limited geographical distribution and the availability of long data-series are necessary to thoroughly address scientific questions related to climate change (Miller-Rushing et al. 2010). The East Atlantic population of light-bellied brent geese Branta bernicla hrota complies with all these demands, and is thus an obvious focal species to assess possible effects of the uneven advancement of spring across the Northern Hemisphere. Advantages associated with this population include a small population size (ca. 7,600 individuals) (Fox et al. 2010), a strict non-stop migration strategy between temperate wintering areas and Arctic breeding areas, and a geographically confined pre-migration spring-fattening area enabling total counts on a daily basis. The population winters in the North Sea region where Denmark is the most important country (Clausen and Percival 1998; Denny et al. 2004). In late spring, $50-75 \%$ of the total population resides in the Danish Agerø area in Western Jutland $\left(56^{\circ} 43^{\prime} \mathrm{N}, 8^{\circ} 34^{\prime} \mathrm{E}\right.$; Fig. 1 ; hereafter referred to as "spring staging area"), where they accumulate fat reserves during spring before leaving on their northbound migration in late May (Clausen et al. 1998; Denny et al. 2004). Light-bellied brent geese are coastal migrants following the west coast of Norway from Denmark to their Arctic destinations, on their way migrating directly past the seasonally staffed Lista

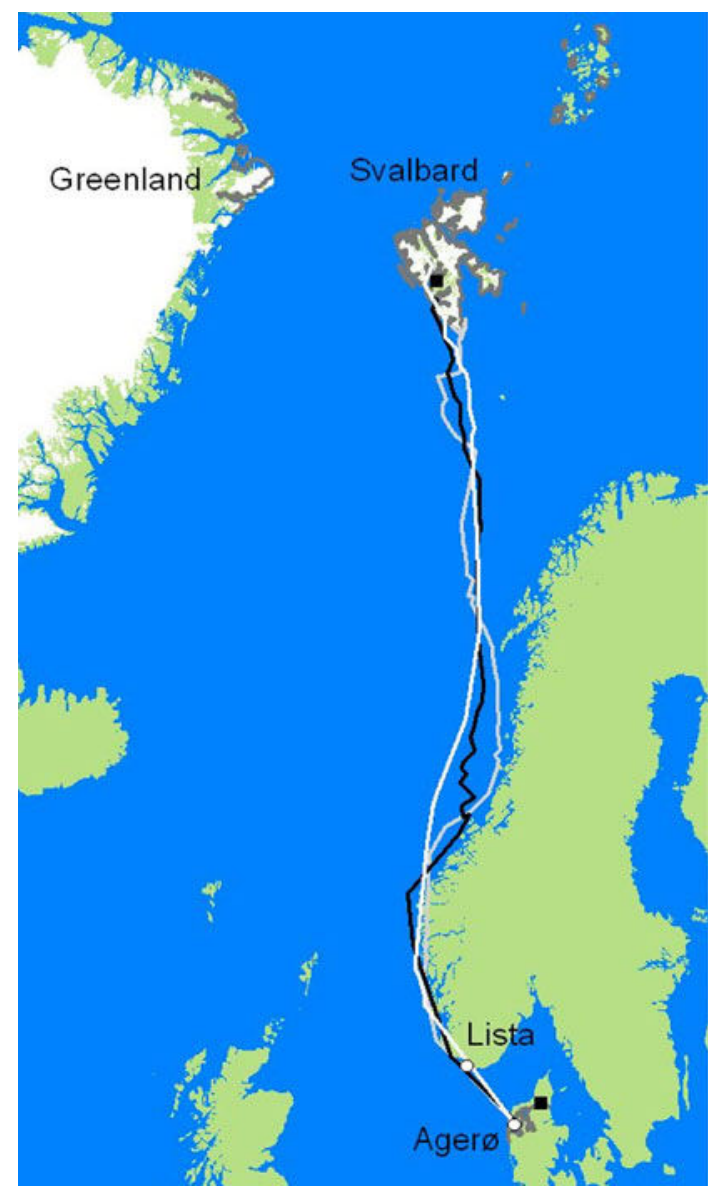

Fig. 1 Spring and breeding distribution of East Atlantic light-bellied brent geese (indicated by solid grey areas), joined by three examples of spring migration routes (black, grey, and white lines) from satellitetracked individuals (Clausen et al. 2003). The main pre-migration staging area (Agerø) as well as the location of the quantitatively important migration spot at Lista Bird Observatory are indicated (white dots), as are also weather stations (solid black quadrats)

Bird Observatory, thereby allowing for exceptional good data on timing of migration (see Fig. 1) (Clausen and Bustnes 1998; Clausen et al. 2003).

When arriving at Svalbard most birds concentrate around fjords in western Spitsbergen or occasionally on Edgeøya in the east to feed on the tundra for 1-2 weeks before finally dispersing to their breeding areas (Mehlum 1998; Clausen et al. 2003). The breeding areas are mainly on small islands on the archipelago ( $\approx 80 \%$ of the population), but an increasing number of pairs also nest at Kilen and other sites in Northeast Greenland $(\approx 20 \%)$ (Clausen et al. 1999). Light-bellied brent geese are long-distance migrants, performing almost non-stop 2,500- to 3,500-km flights with stops only for drinking (as revealed by satellite telemetry studies; Clausen and Bustnes 1998; Clausen et al. 2003). This migratory strategy rely on cues in the temperate staging areas to decide on timing of migration, and prevent the potential re-evaluation of migratory conditions 
en route observed in step-wise migrants (Tombre et al. 2008).

The aim of this study was to assess potential consequences for migrating geese associated with differences in the rate of climatic change along their flyway. We intended to:

1. Investigate the potential advancement of spring in the temperate spring staging areas and Arctic breeding areas of light-bellied brent geese during a 24-year period.

2. Describe the potential change in the concurrent timing of spring migration.

3. Investigate to what extent latitude-dependent climate change might have led to a phenological mismatch between brent goose migration and suitable breeding conditions in the Arctic.

4. Examine the potential effect of this mismatch on annual productivity.

\section{Materials and methods}

\section{Climatic data}

Changes in the onset of spring were quantified by data on accumulated temperature, relying on this measure as a good indicator of relevant processes like snow melt, onset of the growing season and thermoregulatory costs. We applied the date of an accumulated mean temperature threshold of 200 degree days (T200) (Bauer et al. 2008; Sparks et al. 2009; Saino et al. 2011) as a proxy of seasonal advancement, thereby integrating ecological processes across several months. Contrary to climatic snapshot measures (e.g. first day above a threshold temperature or last day of frost), this measure takes into account the climatic situation of the entire pre-migration period. Furthermore, accumulated temperature has been found to be a good indicator of both spring conditions (snow cover, vegetation growth, etc.; Sparks et al. 2009; Saino et al. 2011) and goose migration (Bauer et al. 2008). Data on daily mean temperature in the spring staging area was acquired from a local meteorological station (Aalborg airport, $57^{\circ} 06^{\prime} \mathrm{N}, 9^{\circ} 51^{\prime} \mathrm{E}$ ) run by the Danish Meteorological Institute. Breeding range temperatures (Svalbard airport, $78^{\circ} 15^{\prime} \mathrm{N}, 15^{\circ} 28^{\prime} \mathrm{E}$ ) were extracted from the eKlima platform run by the Norwegian Meteorological Institute. The use of this station as representative of climatic conditions in the breeding areas has several advantages: (1) the station is located in Southwest Spitsbergen, geographically close to the initial areas used by brent geese upon arrival at Svalbard; (2) the station is situated at Isfjorden in a nearcoastal lowland area, thereby representing the actual habitats used by brent geese in the area; and (3) the station has reliable and systematic data on historical weather, enabling the long climatic time-series necessary to investigate climatic trends. Data from more remote sites (Edgeøya, northern Spitsbergen and the island of Hopen) were insufficient to reliably assess temperature trends during the period, but available data from these areas showed a generally high correlation between sites (all correlations $>0.9$ ). Development in T200 was calculated based on 24 years of climate data (1989-2012) from both Svalbard $\left(\mathrm{T}_{200_{\mathrm{SV}}}\right)$ and Denmark $\left(\mathrm{T}_{200_{\mathrm{DK}}}\right)$, corresponding to the timeframe of available and reliable data on brent goose spring migration patterns. It is emphasised that T200 should not be regarded as directly representing the arrival of spring. Rather, it is a proxy of seasonality, so that years with an early spring will translate into a year of early T200. In Denmark T200 ${ }_{\mathrm{DK}}$ may cover the whole period from late winter to mid-spring (February-April), whereas the long Arctic winter on Svalbard will result in a later (June-July) T200 corresponding to Arctic spring and early summer. $\mathrm{T} 100_{\mathrm{SV}}$ was investigated as an alternative proxy of Arctic spring, and temperatures on a few days with no data $(<0.4 \%$ of total days) were interpolated from adjacent records.

\section{Migration patterns}

Timing of spring migration in light-bellied brent geese were inferred from several sources, and combined to a composite and accurate expression of actual departure dates from the Danish spring staging areas. The most reliable records stemmed from observations of large departing flocks in northern Jutland, Denmark and migrating flocks along the west coast of Norway at the Lista Bird Observatory. Additional data were acquired from the online databases of BirdLife Denmark (http:// www.dofbasen.dk) and BirdLife Norway (http://www. artsobservasjoner.no/fugler/), and from the Norwegian http://www.fugler.net organisation. Data from these sources are frequently used as the foundation of scientific literature, but their designation as "citizen science" portals requires that the quality of available data should always be cautiously evaluated. In the present case, where data were restricted to one easily recognised species within a temporally narrow time-frame the scope for misidentification was very limited. However, the observations were carefully evaluated with respect to spatial and temporal overlap, and obvious duplicate records (more than one observer reporting the same migrating flock) were removed prior to further processing. This data filtering was possible because observations from the online databases include date, site name and geographical coordinates, and many have time and flight direction parameters enabling rejection of likely 
identical observations. This was especially important along the southwest coast of Norway, where migrating flocks were observed along a stretch of approximately $300-\mathrm{km}$ coastline, that would have been passed within $4-5 \mathrm{~h}$ of active flight (Green and Alerstam 2000; Clausen et al. 2003).

Our own data from the spring staging areas as well as observations from Lista Bird Observatory allowed us to cross-reference the databases with professional migratory data, which showed no discrepancies between data sources. With consistent patterns across all methods we are confident that our data reflect precise numbers of migrating birds on specific days during migration, and represent a reliable quantitative measure of brent goose departure. Throughout the 1980s data from the online databases were generally scarce and inconsistent, and departing numbers were mainly inferred from declining numbers of birds observed on almost daily counts in the spring staging areas and the migration data from the Lista Bird Observatory. In order to demonstrate the significance of the observational data, we estimated the proportion of the whole flyway population observed on north-bound migration. This was possible by comparison with annual population estimates based on coordinated count activities in the wintering quarters (Clausen et al. 1998; P. Clausen, unpublished data). The timing of the spring departure was calculated by defining the 20,50 and $80 \%$ departure dates, corresponding to the dates in any given year where 20,50 and $80 \%$ of the population had left Denmark on northward migration.

Latitudinal static cues such as day length are generally important to time the onset of migration in geese (Bauer et al. 2008), but here we wanted to investigate how climatic cues might contribute to explain variation in spring departure. To this end we investigated whether T200 in the spring staging areas $\left(\mathrm{T} 200_{\mathrm{DK}}\right.$ ) and spring level (AprilMay) of the North Atlantic Oscillation [NAO; acquired from The National Oceanic and Atmospheric Administration, United States Department of Commerce: http://www. noaa.gov.) might influence departure. Both of these measures represent large-scale climatic circumstances potentially influencing migration phenology (Tottrup et al. 2010).

To quantify the potential change in phenological delay during the 24-year period, "phenological delay" was defined as the number of days between brent goose spring migration and T200 $\mathrm{Sv}$. The first year of data (1989) was used as a reference point, defining the number of days between spring departure and $\mathrm{T} 200_{\mathrm{SV}}$ in this year as a delay of zero. This straightforward and comprehensible approach was justifiable because of 1989 being a wellpredicted year, falling right on the regression line of the strong temporal trend in $\mathrm{T} 200_{\mathrm{SV}}$.
In order to assess whether brent geese had partly compensated for an earlier Arctic spring by shortening their pre-breeding stopover period on Svalbard, we investigated data on nest initiation throughout the study period. Available data covered a total of 6 years, including 1987 and 1991 where direct observations were available from the Svalbard breeding areas (Madsen et al. 1998), and 1997, 2001, 2011 and 2012 where satellite tracking of individual birds allowed for inference of nesting date by recognising the onset of settling in the breeding areas. Such settling was characterised by a very stationary behaviour and recurrent returns to the same small area (the nesting territory) (Clausen et al. 2003; P. Clausen, unpublished data).

\section{Productivity}

Annual productivity (\% juveniles in autumn flocks) was sampled in the autumn staging areas (see Denny et al. 2004) on an annual basis using the distinctive white edges of juvenile wing coverts. This method is both reliable and reproducible, and requires a minimum of training when observing foraging flocks. Counts were carried out in coordinated campaigns involving observers at all wintering sites during monthly surveys from September up to and including January following the protocols described by Lambeck (1990) and Clausen et al. (1998), and care was taken to include all habitats and different flock sizes to reduce problems with differences in age composition (Lambeck 1990).

To assess whether the phenological mismatch might contribute to explain annual variation in productivity (expressed as number of juveniles per adult female), we compiled data on factors previously suggested as being important to reproduction. These included date of snow melt, Arctic fox (predator) abundance, sea ice cover and population size of barnacle geese (potential site competitor) Branta leucopsis (Madsen et al. 1998, 2007), as well as the mismatch variable phenological delay defined in this study. Date of snow melt was expressed as an index describing temporal variation in the timing of snow-free conditions on Svalbard, and was a composite measure of available data from the Norwegian Meteorological Institute's eKlima platform (http://www.eKlima.met.no) covering three weather stations at Hornsund (latitude/ longitude: 77.02/15.57), Sveagruva (77.88/16.72) and Svalbard airport (78.25/15.47), thus ensuring a large geographical scale. Snow melt was defined as the date of $0 \mathrm{~cm}$ snow cover, as measured from either manual readings (average of several point measurements) or automated ultrasound measurements at each station. As climatic conditions vary considerably between sites, the index was normalised by site-specific means across our study period. No single station had time series covering the entire period, 
but our composite measure ensured data from all years. A second snow variable (June snow cover, calculated from the same data set and measured in the same way as date of snow melt) was defined as the annual average snow depth in June, normalised to site-specific means for each of the three weather stations throughout the study period. Data on the abundance of Svalbard Arctic foxes are generally lacking, but an index of population monitoring measuring proportion of winter lairs with cubs (made available by the Norwegian Polar Institute) might serve as an indicator of predatory impacts in the preceding breeding season. This monitoring covers the areas of Kongsfjorden, Adventdalen and Sassendalen on Svalbard, and the index applied was normalised by site-specific means. Comparing this index to the limited available published data (Fuglei et al. 2003) revealed consistent patterns. Sea ice cover was defined as the area of sea ice in a radius of $1 \mathrm{~km}$ from the Svalbard coastline, calculated in ArcMAP 10.0 from data on sea ice distribution provided by the Norwegian Meteorological Institute. The population size of barnacle geese was acquired from Fox et al. (2010) and updated with data from the Wildfowl and Wetlands Trust, UK (courtesy of Dr Larry Griffin). Correlations between explanatory variables were generally $<0.25$, but the two snow variables were highly correlated (Pearsons $r=0.87$ ), and therefore only used separately to confirm the influence of snow on productivity. In addition, the snow variables were somewhat correlated with phenological delay (average Pearsons $r=0.57$ ), probably because all three rely heavily on spring temperatures on the breeding grounds. This made it difficult to identify independent effects of these variables.

\section{Statistical analyses}

Climatic trends and migratory timing were investigated by linear regression, and the climatic influence on departure date was examined by a full factorial general linear model of T200 $\mathrm{DK}$ and spring NAO. Statistical inferences from these analyses were based on $F$-tests, and in all cases assumptions were carefully evaluated prior to analysis. An autoregressive moving average model (ARMA model,; cf. Box et al. 1994) was used to describe variation in productivity. This allowed us to control for potential cyclic patterns and non-independence of data points. The order of autoregressive $(p)$ and moving average $(q)$ parts of the model was evaluated by plotting the partial autocorrelation functions and autocorrelation functions for these estimates, respectively, and identifying the point for which higher orders where basically zero (the Box-Jenkins approach; cf. Box et al. 1994). Model fits were further evaluated using the Akaike information criterion (AIC) (Brockwell and Davis 2009). Factors potentially affecting productivity were investigated by general linear modelling, and candidate models were evaluated using the AIC (Burnham and Anderson 2002). Because of substantial uncertainty in model selection, model averaging was used to derive cumulative AIC weights and estimates of the slope parameter $(\beta)$ of single covariates (Burnham and Anderson 2002).

\section{Results}

Climatic data

T200 ${ }_{\text {DK }}$ showed considerable year-to-year variation [coefficient of variation $(\mathrm{CV})=29.51$ ] with no consistent trend in the 24-year period $(d f=1,22 ; F=0.39 ; P=$ 0.539; Fig. 2a). Thus, an earlier onset of spring could not be supported in the spring staging areas of light-bellied brent geese. In the Svalbard breeding areas T200 ${ }_{\text {SV }}$ showed a more consistent pattern with less variation between years $(\mathrm{CV}=3.73)$. $\mathrm{T}^{200} \mathrm{SV}$ ranged between 23 June (2006) and 25 July (1996), with an average of 14 July. Furthermore, the 24-year period demonstrated a clear advancement of $\mathrm{T}^{200} \mathrm{SV}(d f=1,22 ; F=18.22 ; P<0.001$; Fig. $2 \mathrm{~b})$, corresponding to an earlier onset of spring of 2 weeks. This pattern was unaffected by using $\mathrm{T} 100$ as an alternative proxy for Arctic spring $(d f=1,22 ; F=9.70 ; P=0.005)$.

\section{Migration patterns}

The annual proportion of the total population observed on spring migration averaged $66.5 \%$ and ranged between $19.2 \%$ (2002) and $96.1 \%$ (2003). Across the study period knowledge about departure dates was thus based on generally high numbers of reported migrants, although coverage was best in later years because of the establishment of online databases in Norway (2000) and Denmark (2002). The vast majority of birds took off simultaneously within a relatively short timeframe (2-7 days) in any given year, and the temporal peak of migration was easily recognized, showing consistent patterns across 20, 50 and $80 \%$ departure thresholds (all pair-wise correlations $>0.72$ ). Consequently, in only 2 of the years were the 20 and $80 \%$ departure dates more than 5 days apart (Fig. 3). Migration was more or less normally distributed around peak numbers in late May, and the mean $80 \%$ departure date during the 24-year period was 27 May. Variation in $80 \%$ departure ranged between 24 and 31 May, meaning that the timing of migration was relatively constant throughout the period. No clear change in departure date from the spring staging areas could be found $(20 \%, d f=1,22 ; \quad F=2.72$; $P=0.113 ; 50 \%, d f=1,22 ; F=0.28 ; P=0.560 ; 80 \%$, $d f=1,22 ; F=0.55 ; P=0.466 ;$ Fig. 3$)$. The effect of T200 $0_{\mathrm{DK}}$ on departure date was highly significant 

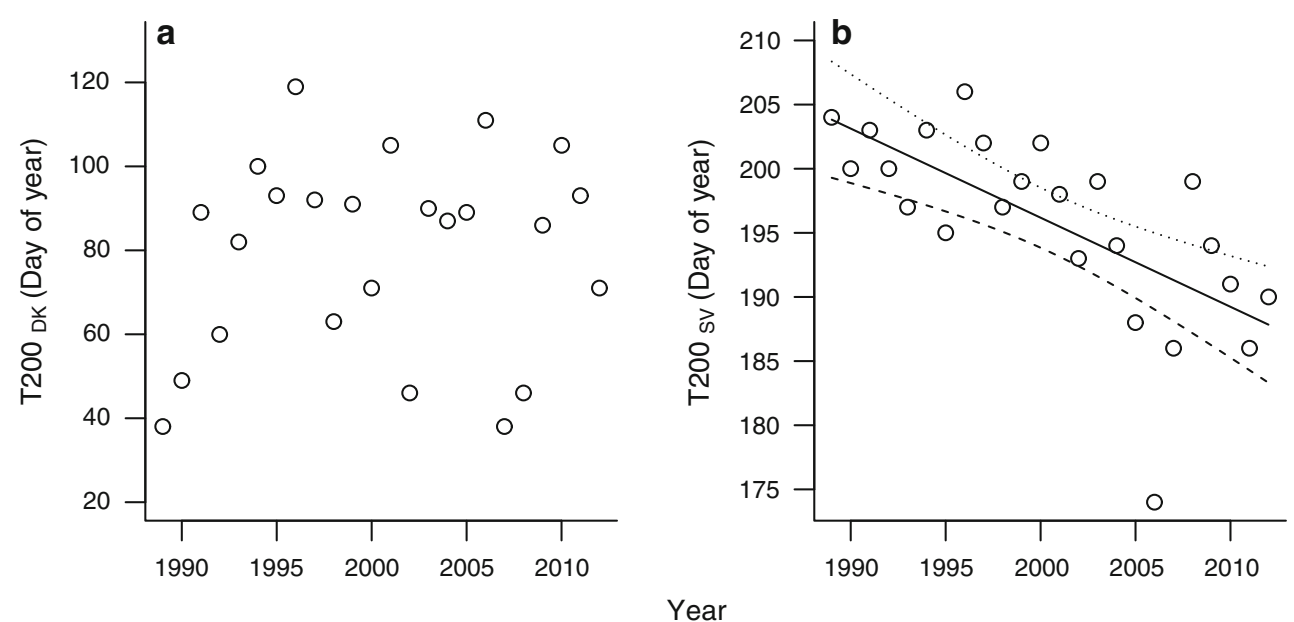

Fig. 2 Development in day of year with 200 accumulated degree days (T200) in the a spring staging areas and b breeding areas of East Atlantic light-bellied brent geese in the period 1989-2012. Lines indicate significant linear regression (solid) with $95 \%$ confidence limits (dashed)

$(d f=1,22 ; F=21.74 ; P<0.001 ;$ Fig. 4$)$, indicating that this factor influenced migratory decisions in brent geese. As a consequence, geese left Denmark earlier in years with an early $\mathrm{T} 200_{\mathrm{DK}}$, and hence, warmer spring temperatures. We found no support for effects of spring NAO ( $d f=1,22$; $F=0.64 ; P=0.434)$ and the interaction between $\mathrm{T} 200_{\mathrm{DK}}$ and spring NAO $(d f=1,22 ; F=0.01 ; P=0.918)$. Phenological delay increased significantly across the time period ( $d f=1,22 ; F=13.46 ; P=0.001$; Fig. 5a), indicating that birds were increasingly lagging behind seasonal advancement on the breeding grounds. This pattern was consistent with the exclusion of the exceptionally warm Arctic spring in 2006 ( $d f=1,21 ; F=19.382 ; P<0.001)$. Available data on nest initiation indicated that timing of nesting was unchanged during the study period ( $d f=1,22$; $F=3.41 ; P=0.138$ ), and because spring departure was likewise unchanged we found no support for a shortening of the pre-breeding Svalbard staging period.

\section{Productivity}

During the study period an average of $29.9 \%$ of the total light-bellied brent goose population was surveyed annually, and productivity showed a distinctive "boom or bust" pattern with large interannual variation. Correlation plots from the ARMA analysis indicated that $P=0$ and $q=3$ [ARMA $(0,3)$ model] was the best model to describe our time-series data, and this outcome was supported by the minimisation of AIC as all other models had $\triangle \mathrm{AIC}$ values $>2$ (Table 1). Based on these findings we fitted a 3-year moving average to smooth the data, which showed a significant decreasing trend during the study period ( $d f=1,22 ; F=10.91 ; P=0.004)$, indicating that juvenile percentages had dropped from approximately $15 \%$ in the 1980 s to roughly $10 \%$ in the 2000 s (Fig. 5b).
The best model to describe variation in productivity was the combined effects of phenological delay and date of snow melt, followed by the sole effect of each of these two variables (Table 2; Fig. 6). Albeit considerable uncertainty in model selection (several models with low $\triangle \mathrm{AIC}$; Burnham and Anderson 2002), all top models included these two covariates. Model averaging indicated slope parameters $(\beta)$ of phenological delay and date of snow melt of -0.30 [95\% confidence interval $(\mathrm{CI})-0.83$ to -0.02 ] and 0.33 (95\% CI 0.03-0.85), respectively. The slope parameters of Arctic foxes, barnacle geese and sea ice cover all had CIs overlapping zero. The cumulative weight for all covariates were 0.74 (date of snow melt), 0.72 (phenological delay), 0.36 (abundance of Arctic foxes), 0.22 (population size of barnacle geese) and 0.09 (sea ice cover). Whereas a bigger phenological delay (corresponding to a greater mismatch) seemed to affect brent goose productivity negatively, date of snow melt was (surprisingly) positively correlated with reproduction, indicating that prolonged snow cover was associated with higher productivity. Replacing the variable date of snow melt with June snow cover only verified this pattern, as re-running the model with this variable revealed a similar result.

\section{Discussion}

Development in the onset of spring

Increasingly earlier spring season has been well documented in Arctic regions around the world, and higher latitudes are often found to be more affected by climate change than temperate and warmer regions (Stone et al. 2002; Parmesan and Yohe 2003; Karlsen et al. 2010). Our data support this view, and demonstrate a clear 

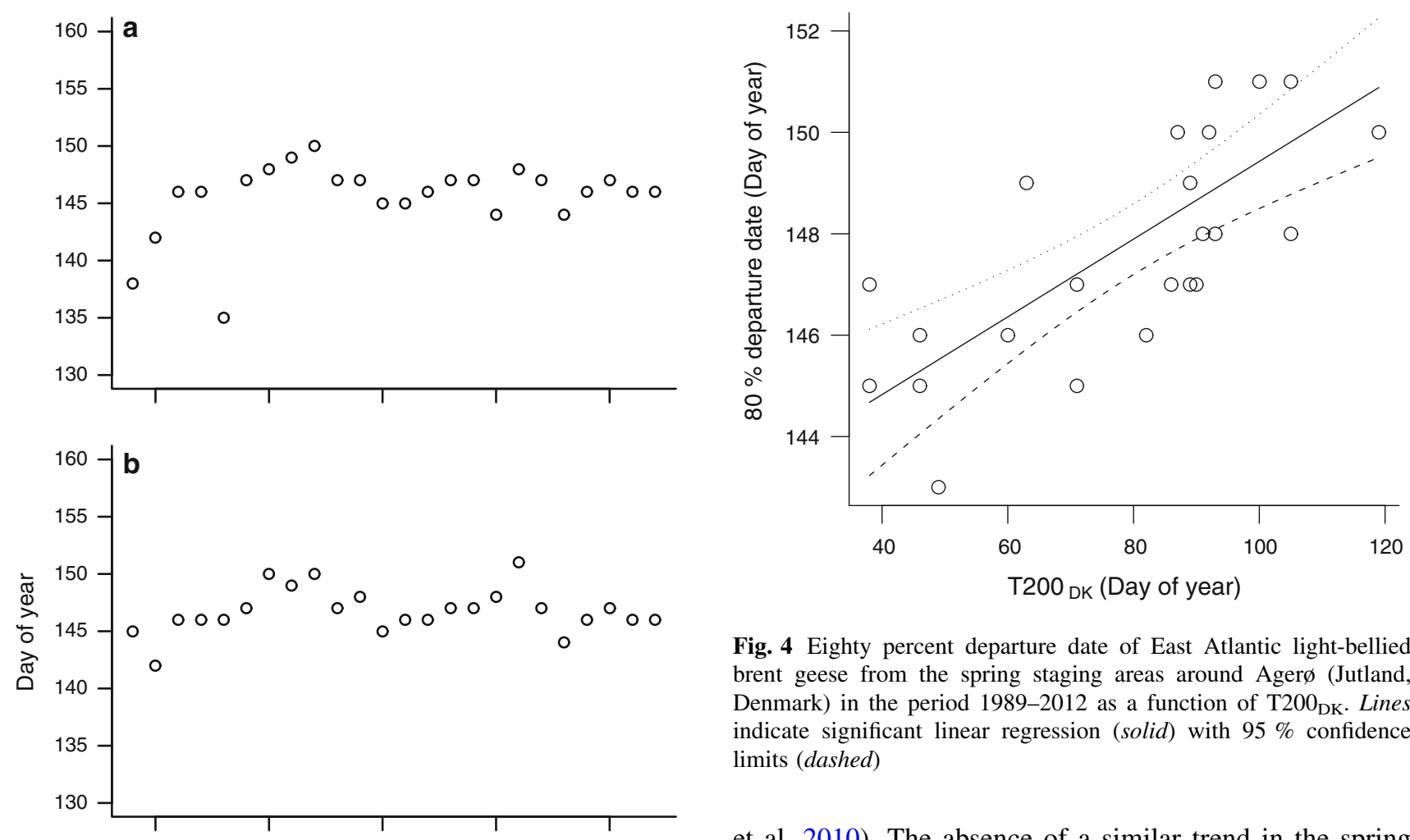

Fig. 4 Eighty percent departure date of East Atlantic light-bellied brent geese from the spring staging areas around Agerø (Jutland, Denmark) in the period 1989-2012 as a function of T200 ${ }_{\mathrm{DK}}$. Lines indicate significant linear regression (solid) with $95 \%$ confidence limits (dashed)

et al. 2010). The absence of a similar trend in the spring staging areas indicated that any development in $\mathrm{T} 200_{\mathrm{DK}}$ was weak enough to go undetected within this time period.

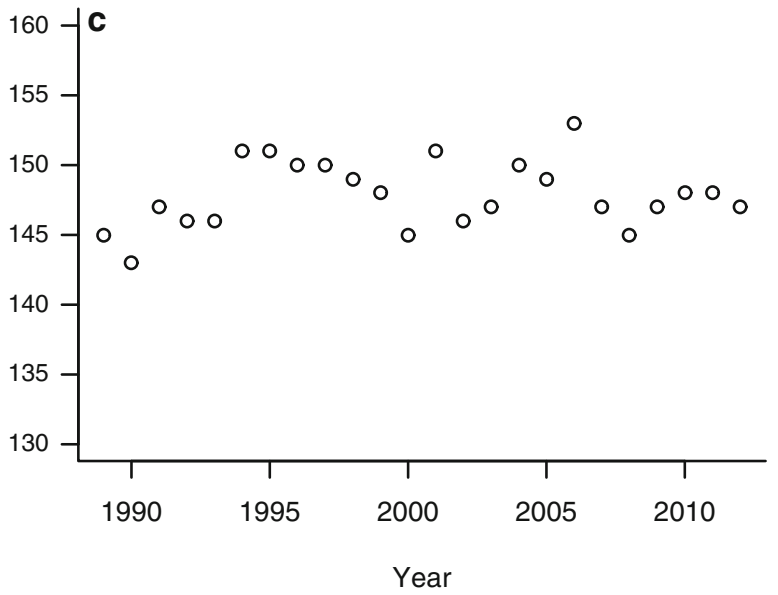

Timing of migration

This study indicates that earlier departure was associated with warmer and earlier springs, a pattern confirmed by Smith et al. (2012) who demonstrated advancing migration among Pacific black brant Branta bernicla nigricans in Canada. The lag in response of departure date of lightbellied brent geese necessary to keep up with an earlier Arctic spring might, therefore, above all be due to the absence of a clear warming trend in their spring staging areas. This suggests that brent geese rely on proximate cues in their immediate surroundings to decide on timing of migration. Bauer et al. (2008) showed that migrating pinkfooted geese Anser brachyrhynchus, travelling a similar route from Denmark via Norway to the Svalbard breeding grounds using several stopover sites en route, use both day length and accumulated temperature as migratory indicators, and that the importance of these factors changed during the course of migration. Thus, day length was a good determinant of migration initiation from Denmark, but only accumulated temperature remained a significant explanatory variable on the stopover sites in Norway, thereby underlining this measure as a solid proxy for the advancement of spring on local scales. The migration pattern shown in this study conforms very well to these findings. Being a long-distance non-stop migrant, brent 

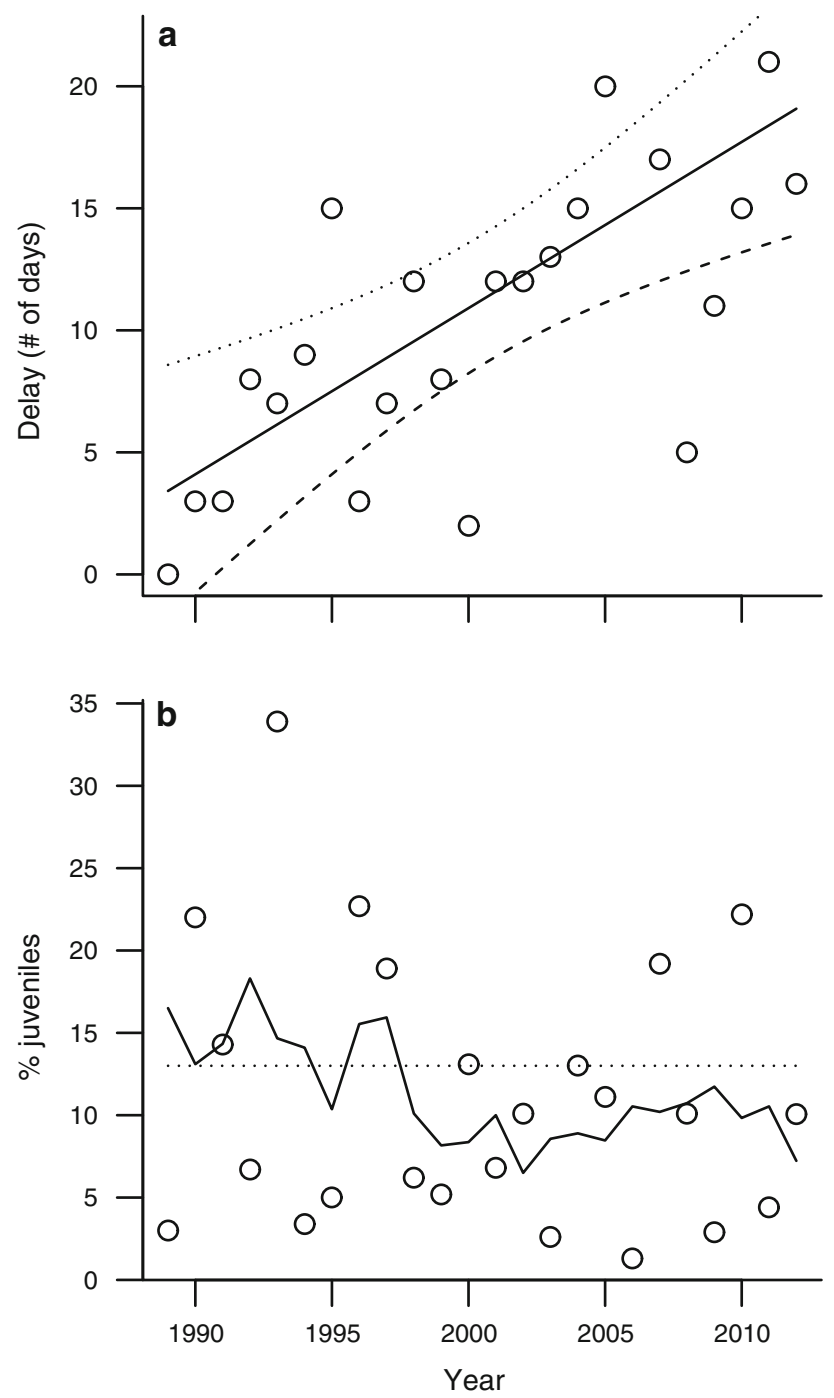

Fig. 5 a Development in phenological delay of East Atlantic lightbellied brent geese during the period 1989-2012. Delay Number of days between brent goose spring migration and T200 $\mathrm{SV}$, and the first year of data (1989) is used as a reference point, defining the number of days between departure and $\mathrm{T} 200_{\mathrm{SV}}$ in this year as a delay of zero. Lines indicate significant linear regression (solid) with $95 \%$ confidence limits (dashed), and the high delay of 2006 (36 days) is omitted for clarity. b Annual productivity (juvenile percentages in autumn flocks) of East Atlantic light-bellied brent geese during the period 1989-2012. Lines indicate a 3-year running average (solid) and average annual mortality in the population (dashed) (Clausen et al. 2001)

geese are unable to synchronize with environmental factors during the course of migration, and consequently they are forced to decide on migratory timing from whatever cues are available in the Danish spring staging areas. The relatively fixed spring departure indicates a migratory pattern relying heavily on day length modified by local spring conditions in any given year.
Table 1 Summary output of the five best autoregressive moving average (ARMA) models to describe brent goose productivity during the period 1989-2012

\begin{tabular}{lllll}
\hline ARMA model $(P, q)$ & $d f$ & AICc & $\Delta$ AIC & Weights \\
\hline$(0,3)$ & 20 & 160.28 & 0.00 & 0.618 \\
$(1,3)$ & 19 & 162.37 & 2.09 & 0.218 \\
$(0,4)$ & 19 & 167.81 & 7.53 & 0.091 \\
$(0,5)$ & 18 & 168.58 & 8.30 & 0.024 \\
$(2,3)$ & 18 & 169.56 & 9.28 & 0.019 \\
\hline
\end{tabular}

$P, q$ Order of autoregressive and moving average parts in the model, $\triangle A I C$ difference in Akaike's information criterion (AIC) value between each model and the model with lowest AIC, Weights weight of evidence in favour of each model being the best fit

The impacts of advancing spring

The ability to adapt to climate change has proven to vary considerably between bird species, and is often associated with the migration strategy of a given population (Boyd et al. 2000; Ahola et al. 2004; Both and Visser 2005; Tombre et al. 2008; Moe et al. 2009; van der Jeugd et al. 2009). Species migrating short distances between breeding and wintering areas are likely to experience similar climatic changes at both sites, and migrants with several stopover sites during the course of migration might be able to frequently re-sample climatic cues and re-evaluate their timing of migration. Long-distance non-stop migrants on the other hand, like the brent geese in our study population, are forced to rely exclusively on climatic cues far away from the breeding areas to decide on timing of migration, and might therefore be especially vulnerable to uneven global warming across the Northern Hemisphere.

The increasing phenological delay among East Atlantic light-bellied brent geese has been paralleled by a simultaneous drop in recruitment from approximately $15 \%$ in the 1980 s to roughly $10 \%$ in the 2000 s. As the average annual mortality rate in this small population is $13 \%$ (Clausen et al. 2001), the current level of productivity might not be enough to counterbalance long-term annual losses. In support of this view, the mild winters and associated low mortality of the early 2000 s resulted in a relatively stable population size, but the return of cold winters and associated elevated mortality in recent years has triggered a decline from approximately 8,200 birds to only 6,700 (Clausen et al. 2001; P. Clausen, unpublished data).

Analyses in this study indicated that higher brent goose productivity was associated with prolonged snow cover. This relationship is of considerable interest, as earlier studies on other species of Arctic geese have shown a negative effect of spring snow on annual productivity (Madsen et al. 2007, Morrissette et al. 2010). Although this pattern could be related to a competitive advantage of brent 
Table 2 Summary output of the AIC modelling procedure, showing performance of the five best models to describe variation in brent goose productivity

\begin{tabular}{|c|c|c|c|c|}
\hline Model & $d f$ & $\mathrm{AICc}$ & $\Delta \mathrm{AIC}$ & Weights \\
\hline Phenological delay + date of snow melt & 4 & -3.9 & 0.00 & 0.411 \\
\hline Date of snow melt & 3 & -1.9 & 1.98 & 0.152 \\
\hline Phenological delay & 3 & -1.1 & 2.78 & 0.102 \\
\hline Phenological delay + abundance of Arctic foxes & 4 & -0.8 & 3.12 & 0.086 \\
\hline Date of snow melt + abundance of Arctic foxes & 4 & -0.28 & 3.70 & 0.064 \\
\hline
\end{tabular}

For abbreviations, see Table 1

Fig. 6 Productivity of East Atlantic light-bellied brent geese (goslings per adult female) as a function of a phenological delay (number of days) and $\mathbf{b}$ date of snow melt in the breeding areas (days from average) in the period 1989-2012. Lines indicate linear regressions (solid) with $95 \%$ confidence limits (dashed)
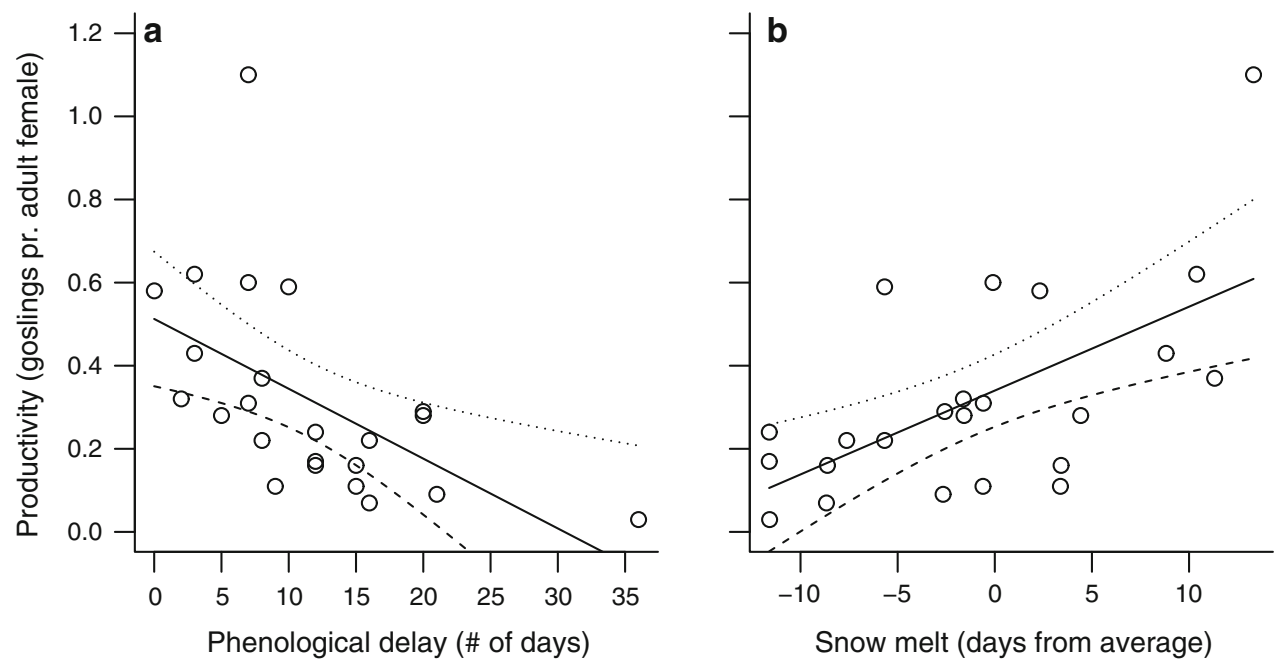

geese in years with late snow melt (brent geese are the last of the Svalbard breeding geese to arrive on the breeding grounds; Madsen et al. 1999), we found no support for competitive effects in this study. Rather, we argue that the effect of snow cover should be seen in connection with the negative effect of phenological delay (the mismatch effect). The relatively high correlation between these two variables hampers causal interpretation, but one explanation might be that later snow melt could have an indirect effect on reproduction by reducing the effect of the phenological mismatch. As such, extended snow cover might partly offset the negative effects of an earlier spring by delaying sprouting and subsequent depletion of tundra vegetation. Arctic tundra ecosystems are characterised by a rapid seasonal drop in nutrient availability, a welldocumented evolutionary force in Arctic breeding geese (Sedinger and Raveling 1986; Sedinger and Flint 1991). Optimal timing of arrival is therefore essential to successful reproduction, and the extreme conditions at these latitudes leave only a small temporal window of ecological and physiological opportunities (Bêty et al. 2004; Madsen et al. 2007; Moe et al. 2009; van der Jeugd et al. 2009). Nesting evolved by means of natural selection to synchronise the hatching of goslings with the maximum availability of high-quality food plants, and several studies have shown that mismatches between breeding and optimal food availability involve a significant reduction in gosling fitness (Sedinger and Raveling 1986; Lepage et al. 1998; van der Jeugd et al. 2009). In the late 1980s/early 1990s (the first years of this study), Madsen et al. (1998) found that hatching in Svalbard-breeding light-bellied brent geese already lagged behind optimal food quality, meaning that goslings were forced to feed on depleted forage of suboptimal quality. Since then, the spring (this study) and the growing season (Karlsen et al. 2010) have advanced by 14 days on Svalbard, whereas brent goose departure dates have remained unchanged. It is therefore very likely that the overlap between food availability and gosling requirements have become even smaller. In years with prolonged snow cover this negative effect might be partly counterbalanced by later vegetation growth, explaining the positive relation between productivity and date of snow melt. Clarifying the exact mechanism-and whether this is related to plant growth and food availability-is dependent on meticulous studies in the breeding areas of this population. In all cases, hatching success, gosling and/or juvenile survival must have been poor in recent years, and with the continued uneven rise in surface temperatures the phenological delay can only be expected to grow in the near future. 
Brent goose breeding success can be influenced by several factors including predation, weather (Madsen et al. 1998) and spring-fattening (Ebbinge and Spaans 1995), and it is unreasonable to believe that any of these factors are unimportant. This study is among the first to demonstrate that climate change might also influence productivity, as indicated by a plausible link between a global warminginduced phenological mismatch and juvenile proportions in autumn flocks. The best-supported variables to describe variation in brent goose productivity (phenological delay and date of snow melt) are both related to seasonal advancement in the breeding areas, and indicate that brent geese might progressively lag behind the short window of opportunity characterising Arctic breeding grounds. To support this view, the extraordinary early spring in 2006 resulted in the lowest ever recorded productivity in the population, where juveniles accounted for only $1.3 \%$ of the total population (Clausen 2006).

An important weakness to fully clarify the suggested impact on brent goose fitness is the lack of recent data from the breeding grounds of this population. This shortcoming is not restricted to brent geese, but highlights the need for updated data on food availability, timing of breeding, predation pressure and interspecific competition on the Svalbard breeding grounds. Clarifying how these circumstances might be influenced by global warming, and understanding how they might affect long-distance migrants with a static migration phenology, is a key step in unravelling what might influence population change. McNamara et al. (2011) pointed out how environmental change might influence the reliability of cues that affect the timing of specific activities, and highlighted the need for better knowledge of proximate factors regulating phenology. Our brent goose case is a prime example in support of the theoretical approach outlined in that study, and underline the importance of studying how optimal timing of life history activities might become increasingly affected by future climatic change. While advancing Svalbard springs might also benefit brent geese by means of glacial retreat potentially exposing new breeding areas (Jensen et al. 2008), it is unknown to what extent this might counterbalance negative effects in the Arctic region. In any case, adapting to new environmental conditions often involves a temporal delay potentially detrimental to this already small population.

\section{Future steps}

For many Arctic-breeding birds the long data series necessary to support climate change research are lacking, and the accelerating latitude-dependent global warming may therefore influence many other migrants exploiting different biomes during their annual cycle. Unravelling how
Arctic-breeding passerines, waders, waterfowl and seabirds might cope with these phenological changes is a major task for conservationists in the coming decades (Post et al. 2009; Miller-Rushing et al. 2010). This is especially true for species relying on long-distance migration. For the Svalbard-breeding population of light-bellied brent geese further research on the Arctic breeding grounds is urgently needed to assess exactly what causes the decline in reproduction. This is the only Svalbard-breeding goose population with no considerable growth in recent decades (Fox et al. 2010), and it seems possible that one contributory factor might be the reliance on a static migration phenology.

Acknowledgments Thanks are due to Jesper Madsen who initiated the long-term monitoring of the East Atlantic light-bellied brent geese. We are particularly indebted to all the committed observers that worked at Lista Bird Observatory during the study period and kindly provided the necessary data, to Guy Q. A. Anderson who contributed to the collection of data in the early 1990s, and to all professional and volunteer observers who help with age counts of brent goose flocks every year. Data from the two Norwegian citizen science portals http://www.fugler.net and http://www.artsobservasjoner.no/fugler/ were extracted and sent to us by Oskar Kenneth Bjørnstad and Tomas Aarvak, respectively, and Nick Hughes provided the data on sea ice coverage. Toke Høye, Jesper Madsen and Tony Fox are thanked for fruitful suggestions to outline the study, and Gilles Gauthier, Hannu Pöysä and two anonymous reviewers for their very constructive comments on an earlier draft.

\section{References}

Ahola M, Laaksonen T, Sippola K, Eeva T, Rainio K, Lehikoinen E (2004) Variation in climate warming along the migration route uncouples arrival and breeding dates. Glob Change Biol 10:1610-1617. doi:10.1111/j.1365-2486.2004.00823.x

Bauer S, Gienapp P, Madsen J (2008) The relevance of environmental conditions for departure decision changes en route in migrating geese. Ecology 89:1953-1960. doi:10.1890/07-1101.1

Bêty J, Gauthier G, Giroux JF, Korpimaki E (2001) Are goose nesting success and lemming cycles linked? Interplay between nest density and predators. Oikos 93:388-400. doi:10.1034/j.16000706.2001.930304

Bêty J, Giroux JF, Gauthier G (2004) Individual variation in timing of migration: causes and reproductive consequences in greater snow geese (Anser caerulescens atlanticus). Behav Ecol Sociobiol 57:1-8. doi:10.1007/s00265-004-0840-3

Both C, Visser ME (2005) The effect of climate change on the correlation between avian life-history traits. Glob Change Biol 11:1606-1613. doi:10.1111/j.1365-2486.2005.01038.x

Box GEP, Jenkins GM, Reinsel GC (1994) Time series analysis: forecasting and control, 3rd edn. Prentice Hall, Englewood Cliffs

Boyd H, Bell MV, Watson D (2000) Spring weather and migration of geese from Scotland to Iceland. Ring Migr 20:153-165. doi: 10.1080/03078698.2000.9674238

Brockwell PJ, Davis RA (2009) Time series: theory and methods, 2nd edn. Springer, New York

Burnham KP, Anderson DR (2002) Model selection and multimodel inference: a practical information-theoretic approach. Springer, New York 
Callaghan TV, Björn LO, Chernov Y, et al. (2004) Biodiversity, distributions and adaptations of Arctic species in the context of environmental change. Ambio 33:404-417. doi:10.1639/00447447(2004)033[0404:BDAAOA]2.0.CO;2

Clausen P (2006) Summer 2006-worst ever breeding season for East Atlantic light-bellied brent geese. GooseNews 6:17-18

Clausen P, Bustnes JO (1998) Flyways of North Atlantic light-bellied brent geese Branta bernicla hrota reassessed by satellite telemetry. Nor Polarinst Skr 200:235-249

Clausen P, Percival SM (1998) Changes in distribution and habitat use of Svalbard light-bellied brent geese Branta bernicla hrota, 1980-1995: driven by Zostera availability? Nor Polarinst Skr 200:253-276

Clausen P, Madsen J, Percival SM, O'Connor D, Anderson GQA (1998) Population development and changes in winter site use by the Svalbard light-bellied brent goose, Branta bernicla hrota 1980-94. Biol Conserv 84:157-165. doi:10.1016/S0006-3207 (97)00097-9

Clausen P, Madsen J, Percival SM, Anderson GQA, Koffijberg K, Mehlum F, Vangeluwe D (1999) Light-bellied brent goose Branta bernicla hrota: Svalbard. In: Madsen J, Cracknell G, Fox $\mathrm{T}$ (eds) Goose populations of the western Palearctic. A review of status and distribution. National Environmental Research Institute, Rønde and Wetlands International, Wageningen. Wetlands International Publication 48, pp 312-327

Clausen P, Frederiksen M, Percival SM, Anderson GQA, Denny MJH (2001) Seasonal and annual survival of east-Atlantic pale-bellied brent geese Branta hrota assessed by capture-recapture analysis. Ardea 89:101-112

Clausen P, Green M, Alerstam T (2003) Energy limitations for spring migration and breeding: the case of brent geese Branta bernicla tracked by satellite telemetry to Svalbard and Greenland. Oikos 103:426-445. doi:10.1034/j.1600-0706.2003.12340.x

Denny MJH, Clausen P, Percival S, Anderson GQA, Koffijberg K, Robinson JA (2004) Light-bellied brent goose Branta bernicla hrota [East Atlantic population] in Svalbard, Greenland, Franz Josef Land, Norway, Denmark, The Netherlands and Britain 1960/61-2000/01. The Wildfowl and Wetlands Trust/Joint Nature Conservation Committee, Slimbridge

Dickey MH, Gauthier G, Cadieux MC (2008) Climatic effects on the breeding phenology and reproductive success of an Arcticnesting goose species. Glob Change Biol 14:1973-1985. doi: 10.1111/j.1365-2486.2008.01622.x

Ebbinge BS, Spaans B (1995) The importance of body reserves accumulated in spring staging areas in the temperate zone for breeding in dark-bellied brent geese Branta-B-Bernicla in the High Arctic. J Avian Biol 26:105-113. doi:10.2307/ 3677058

Fox AD, Ebbinge BS, Mitchell C, Heinicke T, Aarvak T, Colhoun K, Clausen P, Dereliev S, Faragó S, Koffijberg K, Kruckenberg H, Loonen MJJE, Madsen J, Mooij J, Musil P, Nilsson L, Pihl S, Van der Jeugd H (2010) Current estimates of goose population sizes in western Europe, a gap analysis and an assessment of trends. Ornis Svec 20:115-127

Fuglei E, Oritsland NA, Prestrud P (2003) Local variation in Arctic fox abundance on Svalbard, Norway. Pol Biol 26:93-98. doi: 10.1007/s00300-002-0458-8

Green M, Alerstam T (2000) Flight speeds and climb rates of Brent Geese: mass-dependent differences between spring and autumn migration. J Avian Biol 31:215-225. doi:10.1034/j.1600-048X. 2000.310213.x

Høye TT, Post E, Meltofte H, Schmidt NM, Forchhammer MC (2007) Rapid advancement of spring in the High Arctic. Curr Biol 17:449-451. doi:10.1016/j.cub.2007.04.047

IPCC (2007) Climate Change 2007: the physical science basis. Contribution of Working Group I to the Fourth Assessment
Report of the Intergovernmental Panel on Climate Change. Cambridge University press, Cambridge

Jensen RA, Madsen J, O'Connell M, Wisz MS, Tømmervik H, Mehlum F (2008) Prediction of the distribution of Arctic-nesting pink-footed geese under a warmer climate scenario. Glob Change Biol 14:1-10. doi:10.1111/j.1365-2486.2007.01461.x

Karlsen SR, Høgda KA, Solbø S, Storvold R (2010) Mapping of the growing season on Svalbard based on satellite data for the 1985 to 2009 period. Presentation at State of the Arctic Conference, Miami, FL. http://soa.arcus.org/sites/soa.arcus.org/files/sessions/ 2-1-observations-arctic-change/pdf/2-1-9-storvold-rune.pdf

Lambeck RHD (1990) The applicability of age ratio and brood size counts in population dynamic studies of the brent goose Branta b. bernicla. Ardea 78:414-425

Lehikoinen E, Sparks T, Zalakevicius M (2004) Arrival and departure dates. Adv Ecol Res 35:1-31. doi:10.1016/S0065-2504(04) 35001-4

Lepage D, Gauthier G, Reed A (1998) Seasonal variation in growth of greater snow goose goslings: the role of food supply. Oecologia 114:226-235. doi:10.1007/s004420050440

Madsen J, Bregnballe T, Frikke J, Kristensen JB (1998) Correlates of predator abundance with snow and ice conditions and their role in determining timing of nesting and breeding success in Svalbard light-bellied brent geese Branta bernicla hrota. Nor Polarinst Skr 200:221-234

Madsen J, Cracknell G, Fox AD (eds) (1999) Goose populations of the western PaleArctic. A review of status and distribution. National Environmental Research Institute, Rønde and Wetlands International, Wageningen. Wetlands International Publication 48

Madsen J, Tamstorf M, Klaassen M, Eide N, Glahder C, Rigét F, Nyegaard H, Cottaar F (2007) Effects of snow cover on the timing and success of reproduction in high-Arctic pink-footed geese Anser brachyrhynchus. Polar Biol 30:1363-1372. doi: 10.1007/s00300-007-0296-9

McNamara JM, Barta Z, Klaassen M, Bauer S (2011) Cues and the optimal timing of activities under environmental change. Ecol Lett 14:1183-1190. doi:10.1111/j.1461-0248.2011.01686.x

Mehlum F (1998) Areas in Svalbard important for geese during the pre-breeding, breeding and post-breeding periods. Nor Polarinst Skr 200:41-56

Miller-Rushing AJ, Høye TT, Inouye DW, Post E (2010) The effects of phenological mismatches on demography. Philos Trans R Soc (B) 365:3177-3186. doi:10.1098/rstb.2010.0148

Moe B, Stempniewicz L, Jakubas D, Angelier F, Chastel O, Dinesen F, Gabrielsen GW, Hanssen F, Karnovsky NJ, Rønning B, Welcker J, Wojczulanis-Jakubas K, Bech C (2009) Climate change and phenological responses of two seabird species breeding in the high-Arctic. Mar Ecol Prog Ser 393:235-246. doi:10.3354/meps08222

Morrissette M, Bêty J, Gauthier G, Reed A, Lefebvre J (2010) Climate, trophic interactions, density dependence and carry-over effects on the population productivity of a migratory Arctic herbivorous bird. Oikos 119:1181-1191. doi:10.1111/j.16000706.2009.18079.x

Nordli $\varnothing$ (2005) Temperature variations at Svalbard during the last century. Nord Space Act 13:6-7

Parmesan C, Yohe G (2003) A globally coherent fingerprint of climate change impacts across natural systems. Nature 421: 37-42. doi:10.1038/nature01286

Pearce-Higgins JW, Yalden DW, Whittingham MJ (2005) Warmer springs advance the breeding phenology of golden plovers Pluvialis apricaria and their prey (Tipulidae). Oecologia 143:470-476. doi:10.1007/s00442-004-1820-z

Post E, Forchhammer MC, Bret-Harte MS, Callaghan TV, Christensen TR, Elberling B, Fox AD, Gilg O, Hik DS, Høye TT, Ims 
RA, Jeppesen E, Klein DR, Madsen J, McGuire AD, Rysgaard S, Schindler DE, Stirling I, Tamstorf MP, Tyler NJC, van der Wal R, Welker J, Wookey PA, Schmidt NM, Aastrup P (2009) Ecological dynamics across the Arctic associated with recent climate change. Science 325:1355-1358. doi:10.1126/science. 1173113

Saino N, Ambrosini R, Rubolini D, von Hardenberg J, Provenzale A, Huppop K, Huppop O, Lehikoinen A, Lehikoinen E, Rainio K, Romano M, Sokolov L (2011) Climate warming, ecological mismatch at arrival and population decline in migratory birds. Proc R Soc B 278:835-842

Scott DA, Rose PM (1996) Atlas of Anatidae populations in Africa and Western Eurasia. Wetlands International, Wageningen

Sedinger JS, Flint PL (1991) Growth rate is negatively correlated with hatch date in black brant. Ecology 72:496-502. doi:10.2307/ 2937190

Sedinger JS, Raveling DG (1986) Timing of nesting by Canada geese in relation to the phenology and availability of their food plants. J Anim Ecol 55:1083-1102

Smith BD, Hagmeier KR, Boyd WS, Dawe NK, Martin TD, Monty GL (2012) Trends in volume migration chronology in spring staging Pacific black brant. J Wildl Manage 76:593-599. doi: 10.1002/jwmg. 307

Sparks TH, Aasa A, Huber K, Wadsworth R (2009) Changes and patterns in biologically relevant temperatures in Europe 1941-2000. Clim Res 39:191-207. doi:10.3354/cr00814

Stone RS, Dutton EG, Harris JM, Longenecker D (2002) Earlier spring snowmelt in northern Alaska as an indicator of climate change. J Geophys Res (D) 107(D10):4089. doi:10.1029/ 2000JD000286

Tombre IM, Høgda KA, Madsen J, Griffin LR, Kuijken E, Shimmings P, Rees E, Verscheure C (2008) The onset of spring and timing of migration in two Arctic nesting goose populations: the pinkfooted goose Anser brachyrhynchus and the barnacle goose Branta leucopsis. J Avian Biol 39:691-703. doi:10.1111/j. 1600-048X.2008.04440.x

Tottrup AP, Rainio K, Coppack T, Lehikoinen E, Rahbek C, Thorup $\mathrm{K}$ (2010) Local Temperature fine-tunes the timing of spring migration in birds. Integr Comp Biol 50:293-304. doi:10.1093/ $\mathrm{Icb} / \mathrm{Icq} 028$

van der Jeugd HP, Eichhorn G, Litvin KE, Stahl J, Larsson K, van der Graaf AJ, Drent RH (2009) Keeping up with early springs: rapid range expansion in an avian herbivore incurs a mismatch between reproductive timing and food supply. Glob Change Biol 15:1057-1071. doi:10.1111/j.1365-2486.2008.01804.x

Visser ME (2008) Keeping up with a warming world; assessing the rate of adaptation to climate change. Proc R Soc (B) 275:649-659. doi: 10.1098/rspb.2007.0997

Ward DH, Dau CP, Tibbitts TL, Sedinger JS, Anderson BA, Hines JE (2009) Change in abundance of Pacific brant wintering in Alaska: evidence of a climate warming effect? Arctic 62:301-311

Watkinson AR, Gill JA, Hulme M (2004) Flying in the face of climate change: a review of climate change, past, present and future. Ibis 146:4-10. doi:10.1111/j.1474-919X.2004.00321.x 